\title{
CONCENTRACION DE DDT EN Chione californiensis DE LA PARTE NORTE DEL GOLFO DE CALIFORNIA.
}

\author{
por \\ Orlando Núñez Esquer
}

Cienrias Marinas Vol. 2 Núm. I

\section{RESUMEN}

Los bivalvos son organismos filtroalimentadores que tienden a concentrar en su cuerpo los compuestos que se encuentran en solución o en suspensión en el agua, por lo que pueden considerarse indicadores biológicos de las concentraciones de contaminantes alcanzadas en el medio, como el DDT, por este motivo se escogió al género Chione para realizar el presente estudio. Un trabajo similar efectuado en la red de canales de irrigación del valle de Mexicali, muestra concentraciones considerables de DDT (10-20 ppm) en organismos de la misma clase taxonómica y los valores indican un gradiente ascendente a medida que los canales se acercan al mar, lo cual indicó que en la zona de la desembocadura del Río Colorado, se encontrarían concentraciones excesivas, tał vez tóxicas, para especies que allí desovan, tan importantes como. Penaeus (camarón) v Cynoscion (totoaba). Por estos motivos dicha zona se dividió en dos áreas en las cuales fueron colectados organismos del género Chione y sedimentos, determinando sus concentraciones de DDT por cromatografía de gases. Sin embargo, los valores determinados van muy por débajo de lo esperado (alrededor

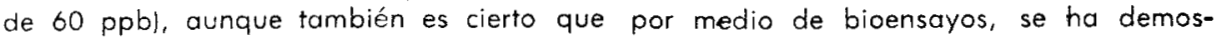
trado que concentraciones tan bajas como 0.2 ppb en el agua, causa el $100 \%$ de mortalidad en camarones adultos y que valores aún mucho menores afectan la reproducción y el crecimiento de estos organismos. Algo notable es el hecho de que se encontraron concentraciones mayores en las muestras colectadas a mayor distancia de la la zona de aporte de pesticidas, esto puede ser importante para el establecimiento de un patrón de circulación general de estos contaminantes lo cual constituye la siguiente fase del presente trabajo.

\section{INTRODUCCION}

Este estudio fue realizado en la Unidad de Ciencias Marinas dependiente de la Universidad Autónoma de Baja California y formó parte de un estudio oceanológico auspiciado bajo contrato por la Secretaría de Recursos Hidráulicos.

Se ha demostrado en experimentos de laboratorio, que el DDT afecta el crecimiento, la reproducción y la mortalidad de gran cantidad de especies en concentraciones que existen comúnmente en los medios ambientes marinos cercanos a las costas (SCEP, 1973), aún considerando que las interacciones de todos los componentes del ecosistema marino pueden hacer variar notablemente esas concentraciones, es evidente que constituyen un factor importante $y$ puede ser decisivo para el equilibrio ecológico de zonas como el Alto Golfo de California, a donde se tiene la certeza de que se están incorporando cantidades considerables de insecticidas (Nishikawa y otros, no publicado) y que en los últimos años se ha observado un decremento en su potencial biológico-pesquero (Avalos, 1974, Woodwell 1967) demostró que del DDT total que es aplicado por medios aéreos, sólo el $50 \%$ cumple con su misión, quedando adherido a las hojas de las plantas o incorporándose al sustrato y el 50\% restante, queda en la atmósfera en forma de vapor o adherido a partículas para ser transportado por el viento hasta que se preecipita por acción de la lluvia. Los insecticidas que quedan sobre el sustrato, son transportados por los escurrimientos de agua hacia los ríos o a los drenes para llegar generalmente al mar en donde son incorporados a los organismos afectando fundamentalmente las reacciones enzimáticas diel metabolismo y por ende su fisiología redundando como 
es lógico en el equilibrio ecológico de la zona, aunque es importante mencionar, que el aporte actual de insecticidas al ecosistema de la zona en estudio se debe más bien al transporte eólico, ya que no existe contacto directo entre los cuerpos de agua duice y salobre con el mar (Nishikawa y otros, no publicadol salvo en las épocas de lluvia abundante las cuales son escasas.

Con lo dicho anteriormente y para dar una idea aproximada de las cantidades que cada año se están incorporando al Alto Golfo de California, diremos que de 1971 a 1973 se aplicaron en el Valle de Mexicali 900 toneladas de DDT y formulaciones conteniéndolo (Nishikawa y otros, no publicadol. Otra posible fuente de aporte de insecticidas por acarreo eólico la constituyen los valles $1 \mathrm{~m}$ perial y Yuma de los Estados Unidos de Norteamérica, dada su cercanía a la zona de estudio. Los vientos dominantes la mayor parte del año tienen una dirección NW-SE (Alvarez, no publicado). Los compuestos organoclorados a los cuales pertenece el DDT, son de los insecticidas que causan mayores problemas residuales, ya que su tiempo de degradación a compuestos menos tóxicos es prolongado. La persistencia de organoclorados en peces puede observarse en el cuadro siguiente:

$\begin{array}{lc}\text { Insecticida } & \text { Persistencia } \\ \text { DDT } & 5 \text { meses } \\ \text { DDD } & 6 \text { meses } \\ \text { Toxafeno } & 6 \text { meses } \\ \text { Dieldrina } & 1 \text { mes } \\ \text { Heptacloro } & 1 \text { mes }\end{array}$

Estos valores sólo pueden tomarse como referencia, ya que fueron determinados bajo condiciones controladas $y$ es lógico suponer que los diversos factores ambientales, pueden hacerlos variar notablemente.

La acumulación de DDT en el agua es casi insignificante, dado que es prácticamente insoluble en ella $(0.1 \mathrm{ppb})$, en cambio en los animales, la acumulación y su persistencia es mucho mayor, ya que sie solubiliza fócilmente en los tejidos grasos en donde pueden ser retenidos por un tiempo largo aún no determinado (Nishikawa y otros, no publicado).
La sintomatología que presentan los insectos al intoxicarse con DDT, es la siguiente: primeramente, el animal pasa por una fase de excitación nerviosa y convulsiones violentas; esta fase va disminuyendo en intensidad hasta que se produce la incoordinación motriz, en estas condiciones el insecto queda inmovilizado y así vive dos o más horas hasta que muere. (Nishikawa y otros, no publicadol. Evidentemente estos síntomas, denotan una clásica intoxicación del sistema nervioso; a nivel bioquímico fisiológico, lo que ocurre es lo siguiente: los estímulos externos se transmiten de un punto del cuerpo a otro a través de un cambio en la concentración de iones en los nervios, el estímulo es transportado más allá de la neurona o célula receptora en forma de acetil-colina la cual se difunde produciendo la respuesta al estímulo, una vez que la acetil-colina ha provocado la respuesta correspondiente ha de ser eliminada para que el receptor pueda restablecerse para un estímulo futuro, o para evitar respuestas incontroladas de un mismo estímulo; la eliminación de la acetil-colina, se efectúa por hidrólisis del compuesto; esta reacción bioquímica está catalizada por la acetil-colinesterasa, en organismos contaminados con DDT, esta enzima es inhibida y el órgano receptor no podrá restablecerse originando convulsiones, parálisis y finalmente la muerte (McGilvery, 19701 .

La ATP-asa de las biomembranas es una enzima que proporciona energía para el transporte de iones como $\mathrm{Ca}^{+}, \mathrm{Na}^{+}$ y $\mathrm{K}^{+}$a través de la membrana celuiar (Skou, 1965), el DDT inhibe esta enzima bloqueando el transporte iónico y a esto se puede deber el adelgazamiento del cascarón de los huevos de algunas aves y la conducta anormal observada en poblaciones que han sido contaminadas por él. Se ha encontrado que la presencia del DDE (metabolito del DDT), inhibe a la anhidrasa carbónica (Bitman, Cecil, Fries, 1970) siendo esta enzima indispensable para la depositación del carbonato de calcio en los cascarones de los huevos y para el mantenimiento de un gradiente de $\mathrm{pH}$ a través de las membranas celulares (SCEP, 1973). 
NUN̄EZ ESQUER

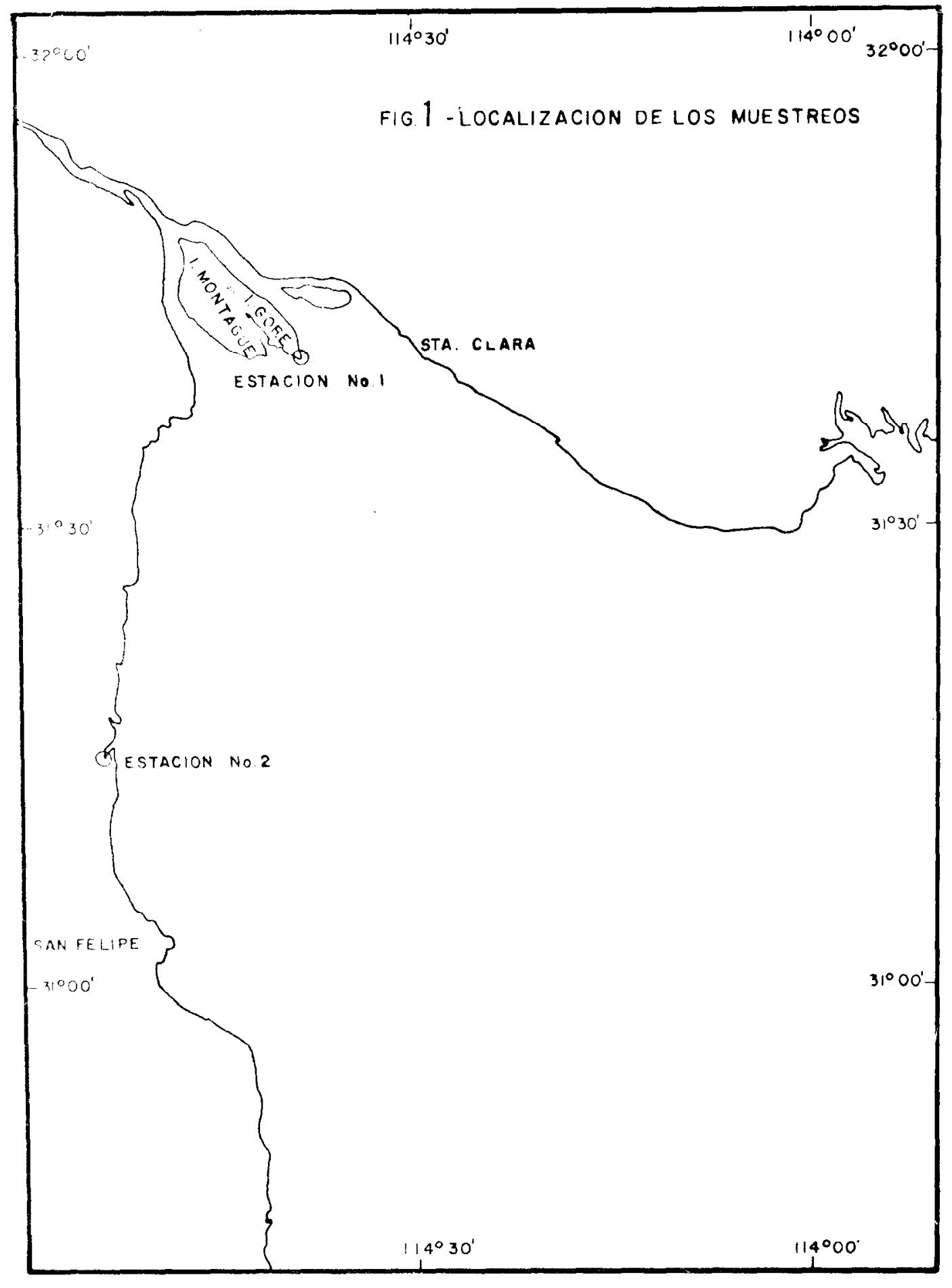


E) DDE induce: enzimas oxidasas de funciones mixtas que hidroxilan y producen compuestos solubles en agua; las hormonas tales como estrógeno, testosterona (Coney, 1967 Peakall, 1970) y tiroxina (Schwartz, 1969) son metabolizadas a mayor velocidad cuando estas enzimas son inducidas; experimentos de laboratorio muestran concentraciones muy bajas de estrógeno en pichones contaminados con DDE (SCEP, 1973).

Recientemente se ha encontrado que el DDT produce anemia en el hombre; se han hecho relaciones entre intensidad de aplicación de DDT y el ídice de anémicos y se ha encontrado una clara relación, y lo más importante es que la anemia producida por este contaminante no responde al tratamiento médico común (Avendaño, comunicación personal) aunque esto no está demostrado aún.

Con lo anteriormente expuesto, se manifiesta la importancia que adquiere la realización de investigaciones exhaustivas sobre insecticidas organoclorados particularmente DDT y sus metabolitos, ya que es evidente el daño que están causando a los organismos y el peligro que representan para el equilibrio ecológico de la biósfera terrestre.

El propósito de este trabajo es el de determinar los niveles de concentración de DDT en almejas del género Chione californiensis ampliamente distribuidas en la zona del Alto Golfo de California y así contribuir con información al mejor conocimiento del problema que constituye este contaminante en la zona mencionada y tener argumentos suficientes para tratar de evitar que adquiera proporciones ecológicamente desastrosas; también se pretende buscar una relación entre las concentraciones de DDT y las variaciones de abundancia que han sufrido los recursos pesqueros más importantes de la región (camarón y totoaba). Asimismo, mediante una interpretación de los resultados obtenidos se tratará de establecer un sistema de circulación general de pesticidas en la zona.

\section{METODOS Y MATERIALES}

La zona se dividio en 2 estaciones (Fia. 1), en las cuales se colectaron al-

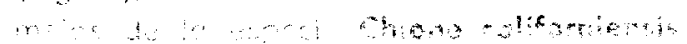

caliza en el extremo sur de la isia Gore, la cual está enclavada en lo que fue la desembocadura del Río Colorado. En este lugar se observa una gran turbidez de las aguas. La segunda estación se encuentra a $30 \mathrm{~km}$ al norte del puerto pesquero de San Felipe, B. C., en un estero lodoso de condiciones similares a la anterior. Las 2 estaciones quedan expuestas a la desecación durante las bajas mareas, gracias a lo cual pudo efectuarse la colecta de las muestras de una manera directa. Las colectas de organismos se hicieron en el mes de agosto de 1973, las muestras fueron colocadas en bolsas de papel aluminio para evitar el contacto de las mismas con plásticos o resinas que pudieran irirroducir error en los análisis. En seguida fueron congeladas en hielo seco $\left(\mathrm{CO}_{2}\right.$ sólido) inmediatamente después de ser empacadas para detener la actividad enzimática que pudiera alterarlas. En las 2 estaciones se hicieron determinaciones "in situ" de temperatura, salinidad y conductividad -con un termohalino-conductimetromarca "Beckman", Mod. RS5 con el fin de buscar alguna relación entre residuos de insecticidas y variaciones de los parámetros mencionados.

De los organismos obienidos se extrajeron los tejidos y se llevó a sequedad en un horno a $60^{\circ} \mathrm{C}$ durante $24 \mathrm{Hrs}$. en navecillas de papel aluminio; en seguida se pulverizaron las muestras en un mortero lavado con hexano (después de cada muestral y se tomó una alícuota de 500 a $300 \mathrm{mg}$. en una pipeta Pasteur empacada con lana de vidrio. Con alúmina activada $\mid \mathrm{Al}_{2} \mathrm{O}_{3}$ a $400^{\circ} \mathrm{C}$ durante 24 Hrs.) se llenó otra pipeta Pasteur empacada de la mișma manera; se colocó la pipeta que contenía la muestra sobre la que contenía la alúmina uniéndola con un conector de teflón; se eluyen los insecticidas y otros compuestos vertiendo hexano en la pipeta superior hasta recoger $9 \mathrm{ml}$. de la pipeta inferior en un tubo de centrífuga de $15 \mathrm{ml}$. En la alúmina quedaron todos los compuestos lipoides $y$ en el eluído quedaron los compuestos de interés en solución con el hexano. En seguida se evaporó a seauedad

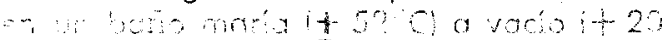

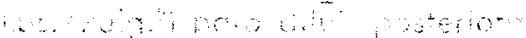


NUNTEZ ESQUER

FIG. 2 - CONCENTRACIONES PROMEDIOS EN LOS ORGANISMOS DE CADA ESTACION
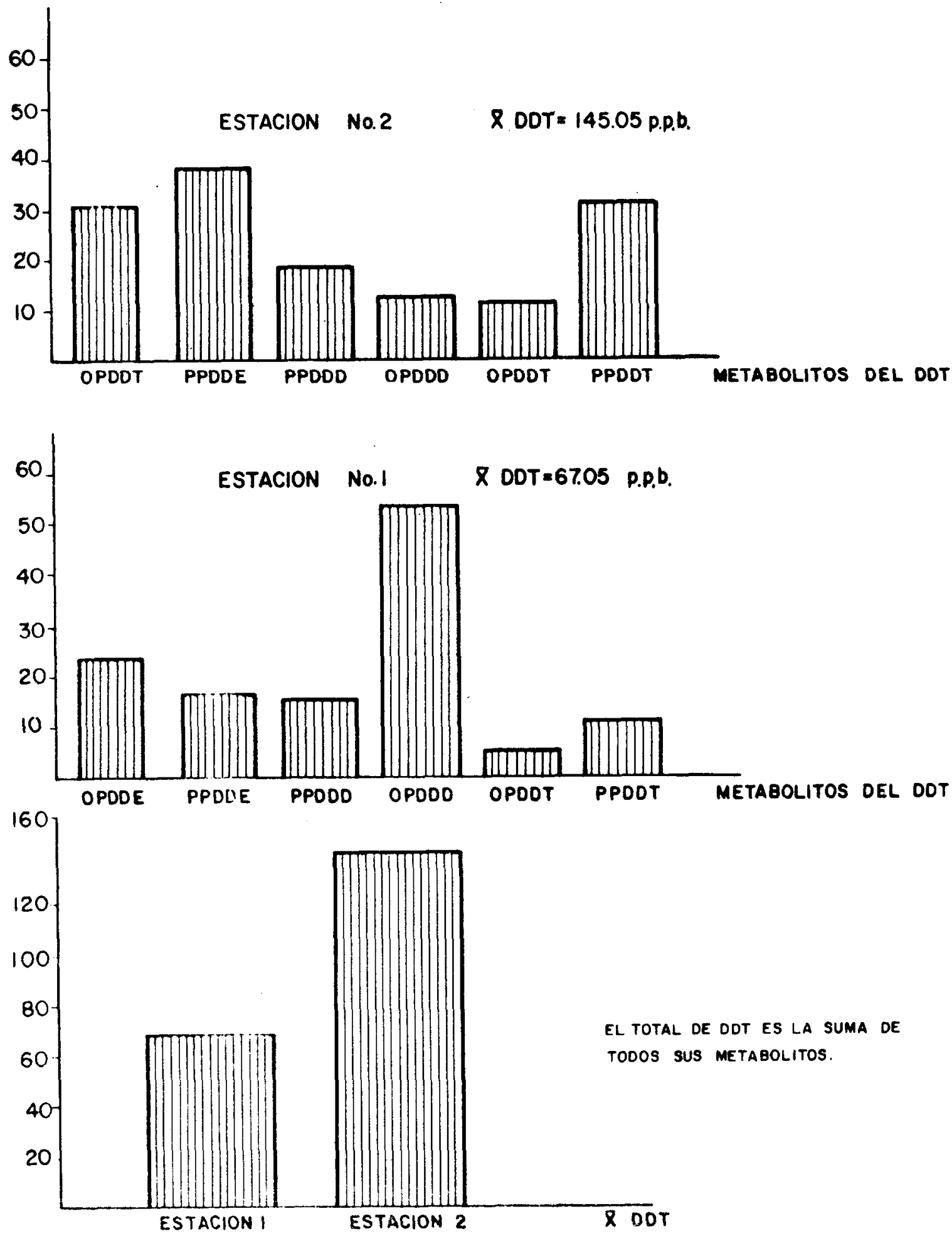
DDT Y SUS METABOLITOS EN CHIONE CALIFORNIENSIS

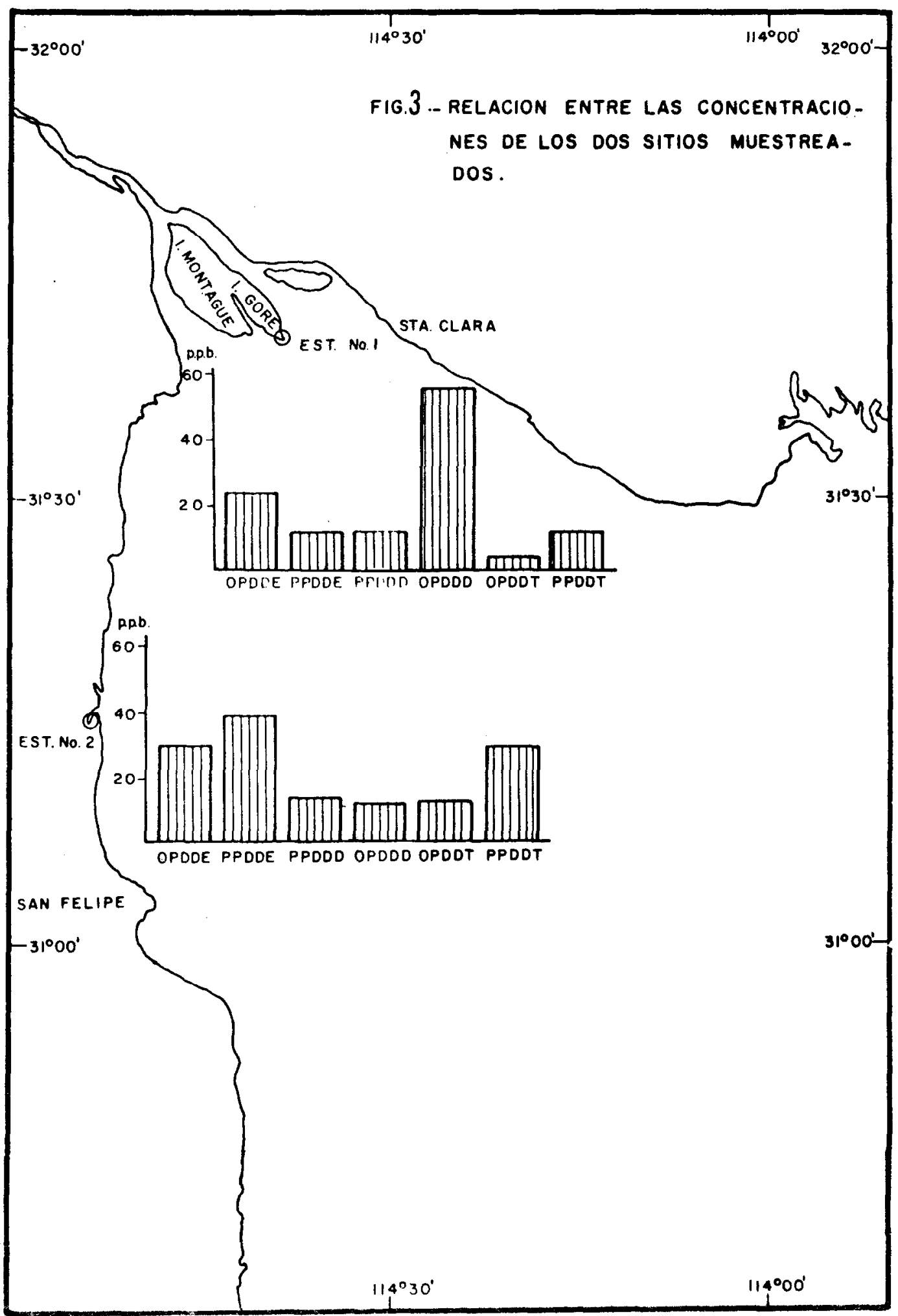




\section{NUNNEZ ESQUER}

50 microlitros de isooctano. De este extracto se inyectaron de 1 a 10 microlitros con una microjeringa a un cromatógrafo de gases marca "Hewlett Packard", Mod. 5750 B que registra mediante un detector de captura de electrones todos los compuestos de la muestra así como su cantidad, entre ellos el DDT y sus metabolitos y los describe mediante un graficador. La identificación de compuestos se hizo mediante una comparación de los tiempos de retención en la columna cromatográfica de soluciones estándar con los tiempos de retención de las muestras. Asimismo, para determinar las concentraciones de cada compuesto se hizo una comparación del área engendrada por las curvas de los estándares y e! área de las curvas de las muestras, asumiendo que fueron inyectadas en condiciones similares.

\section{RESULTADOS Y DISCUSION}

En las figuras 2 y 3 pueden apreciarse gráficamente las concentraciones promedio de cada uno de los metabolitos, así como el total de DDT en los organismos de los dos sitios muestreados. En la estación número 1 se detectó un promedio de 67.05 pplo de DDT lel total de DDT se reporta como la suma de OPDDE, PPDDE, OPDDD, OPDDT, PPDDT, PDDDD, todos ellos metabolitos de este compuestol.

Considero importante el hecho de haber encontrado un promedio de 145.05 $\mathrm{ppb}$ en la estación número dos a pesar de encontrarse ésta mucho más distante geográficamente de la zona que constituye el aporte principal de insecticidas. Esto puede deberse a dos posibles factores: primero, que haya un giro de corrientes en sentido contrario al de las manecillas del reloj, lo cual haría que los contaminantes que provengan del delta del Río Colorado acarreados por las aguas, lleguen primero a la zona costera de Baja California para llegar a la zona costera de Sonora sóla después de haber recorrido una larga distancia, incorporándose en parte a organismos, a materales en suspensión o depositándose en el lecho marino. Esta posibilidad va de acuerdo con Thompson (1969) un encomb indisiss de este tipo de

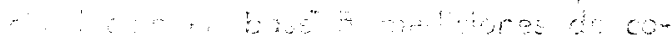

rrientes, distribución de sedimentos, turbidez y orientación de rizaduras de playa a lo largo de la costa de Baja California. Recientemente los estudios de Flores y Galindo (1974) han encontrado indicios de este tipo de circulación en el Alto Golfo en base a mediciones hidrográficas realizadas en dicha zona. Los estudios de García de Ballesteros y Larroque (1974) aportan más evidencias a esta posibilidad pues se encontró una gran cantidad de partículas en suspensión en lo que fue la boca del Río Colorado y que la turbidez causada por estas partículas se extiende más hacia el sur en la zona costera de Baja California que en la de Sonora. Asimismo, Farfán (1974) encontró que las concentraciones de biomasa planctónica son mayores en las costas de Baja California que en las de Sonora. Todos estos argumentos contribuyen a la evidencia de que existe una corriente en este sentido. La mayor abundancia de materiales en suspensión y de plancton en la zona cercana a la segunda estación, puede ser la causa de haber encontrado allí una mayor cantidad de residuos de DDT, pues este compuesto se incorpora a los organismos planctónicos y a los materiales en suspensión los cuales son asimilados por las almejas al filtro-alimentarse.

El segundo factor que pudo haber contribuido a que se hayan encontrado los valores más altos de residuos en la estación número dos es el viento. Si existe una predominancia de los vientos en dirección de la segunda estación los insecticidas organoclorados debido al viento se depositarán en mayor cantidad en esa área; esta posibilidad es reforzada por los estudios de Alvarez (No publicadol, quien encontró que los vientos dominantes en la mayor época del año, tienen una dirección NW-SE o sea en dirección a la zona de estudio.

Estos dos tactores son los únicos considerados para dar una explicación al hecino de haber encontrado mayor cantidad de residuos de DDT en la estación número dos que en la número uno ya que el acarreo hidráulico de este contaminante puede considerarse despreciable pues las precipitaciones en la zona te- 
lifornia son casi nulas durante todo el año.

\section{CONCLUSIONES:}

Las especies que forman parte constitutiva del ecosistema de la parte norte del Golfo de California están acumulando en sus organismos residuos de DDT y dado que la mayoría de estas especies son utilizadas como alimento humano, los consumidores están expuestos a sufrir los efectos fisiológicos producidos por este contaminante.

EI DDT detectado en el Alto Golfo de California es una amenaza que se cierne sobre el equilibrio ecológico de esta zona y que podría contribuir a la disminución de la abundancia del recurso pesquero más importante de la región como lo es el camarón. No es muy remota la posibilidad de que este contaminante también haya contribuido en parte a llevar a las puertas de la extinción a la totoaba que anteriormente constituyó un recurso importante para las pesquerias de la región.

Para tratar de demostrar lo anterior es evidente la importancia que tiene la realización de estudiọs más profundos sobre el tema, como sería por ejemplo, una investigación sobre efectos fisiológicos del DDT en especiese marinas comercial y ecológicamente importantes.

\section{BIBLIOGRAFIA}

Alvarez, L. G. Vientos en la Baría de Todos Santos. Instituto de investigac ones Oceanológicas. U.A.B.C. No Publicodo.
Avalos. M. H. 11974). Anjisis del desarrallo de los pesquerias dé camaron y la totodoa. Tesis Profesional. Unidad de C.encess Mariras. U.A.BC

Bitmian, J., Ger: H, and Fries, G. F. 1970! DOT nduced inhibition of ovian shell g'and caroonic antudrose a mechonisin for inn eggsshells. Science 103.

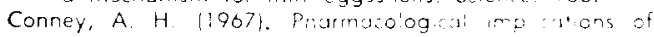

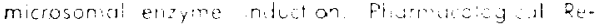
view 19.

Farfan, B. C. (1974). Estimacion de biomasa de zoolancton en la zona norte del Golfo de Califorma. Tesis profesional. Unidad de Ciencias Marmas. U A B.C.

Flores, B. P Galindo L. B. 11974 . Hidrogrotia del Alto Golfo de Colifornia. Tesis protesional. Unidod de Ciencias Marinas. U.A.B.C.

García, de Ballesteros G. y Michel Larroque 119741. Elementos sobre la distribucion de turbidez en el Alio Golfo de California. Ciencios Mormus (1) 2. 1-30 Tesis profesional. Uridod te Ciencias Marinas. UABC

Jackson. Wes. 11971!. Man unci tine Environment. Wh. C Brown Company Publishers Library of Congress Cotolog card number $72-86732$ pp. $81-89$.

Koelle, G. B. (19631. Cholinesterase and antieholimesterase Agents. Handbucir der Expla. Pharmacologie Suppl, 15, Springer Varlag.

Man's Impact on the Global Fnvironment. Report of the Siudy of critical Environmental Problems (SCEP) [1970). The Mossachusetts Institute of Teshnology. pp. $126-136$.

Mc Gilvery, R. W. 119701. Bioquimica, Nueva Editorial Interamericana, S. A. de C. V. Primera edición. pp. $99-105$.

Nishikawa, K. K. y otros. Fstuilo quimico s.abre la concentración de insecticidas crganoclorados en organismos de la parte nurte de Golto de Californa y desembocadura del Río Colorado. Instituto de investigaciones Oceanoligicas, U.A.B.C. No publicado.

Peakall, D. B. (1970). P.P.DDT: Effect on critium metobolism and concentration of estrodol in the blood. Science, 168.

Schwartz, H. L., Kosyreff $W$. Surks $M$ and Oppenhermer 119691. J. H. Increased deiodimation of L. Thyroxine and L-trilodolyronine by liver microsomes from rots treabed with phenobarbital. Nature 221

Skou, J. C. (1905). Enzymatic basts for active transport of $\mathrm{No}$ and $k$ across cell membrane. Physialogica Reviews, 45.

Woodwall, G M. Nurster, C. F., and Isacson, $\bar{F} A$ 119671. DDF residues in an east coast stuary: $A$. case of biological concentration of a persistent insecticide. Scionce 156: 821-824 